\title{
THE INTERNATIONAL CONGRESS OF MATHEMATICIANS
}

\section{CAMBRIDGE, MASSACHUSETTS}

From August 30th to September 6, nineteen hundred and fifty, an International Congress of Mathematicians was held at Harvard University under the auspices of the American Mathematical Society. In addition to the principal host, Harvard University, the following acted as co-hosts: The American Academy of Arts and Sciences, Boston College, Boston University, the Massachusetts Institute of Technology, and Tufts College.

This was the first International Congress of Mathematicians held in the United States since that assembled in connection with the Chicago World's Fair in 1893. At that time an international gathering of mathematicians met at Northwestern University under the presidency of Professor William E. Story of Clark University. Professor Felix Klein of the University of Göttingen attended this Congress as the official representative of the German government and brought with him a number of papers by prominent foreign mathematicians. These papers formed an important part of the program of the meetings which were attended by twenty-five mathematicians. The 1950 Congress was the first International Congress of Mathematicians held on the North American Continent since that in Toronto in 1924.

At the International Congress in Oslo in 1936, the American delegation invited the mathematicians of the world to hold their next general gathering in the United States in 1940. Plans had been practically completed for such a gathering at Harvard University when the outbreak of World War II necessitated the cancellation of the Congress. At the close of the War in 1945, the Council of the Society at once began discussion concerning the possibility of a gathering of the mathematicians of the world. Those guiding the policies of the American Mathematical Society were insistent that there should be no international congress until such a time that the gathering could be truly international in the sense that mathematicians could be invited irrespective of national or geographic origins. On December 10, 1947, the Council of the Society voted unanimously to accept the recommendation of the Emergency Committee for the International Congress of Mathematicians that steps be taken at once to elect offcers and committees for the next congress.

Early in 1948, the following officers of the Congress were elected: President Designate: Oswald Veblen, Institute for Advanced Study; 
Secretary: J. R. Kline, University of Pennsylvania; Associate Secretary: R. P. Boas, Jr., Mathematical Reviews.

Garrett Birkhoff was elected chairman of the Organizing Committee with $\mathrm{W}$. T. Martin as vice chairman. The other members of this committee, as finally constituted, were: A. A. Albert, J. L. Doob, G. C. Evans, T. H. Hildebrandt, Einar Hille, J. R. Kline, Solomon Lefschetz, Saunders MacLane, Marston Morse, John von Neumann, Oswald Veblen, J. L. Walsh, Hassler Whitney, D. V. Widder, and R. L. Wilder. ${ }^{1}$

Invitations to send delegates to the Congress were sent to national academies and royal societies, universities and colleges, and to the mathematical societies throughout the world. In the case of all national academies and royal societies of countries with which the United States Government maintained diplomatic relations, these invitations were transmitted through the diplomatic mail pouch of the State Department. The various mathematical societies cooperated by distributing to their members invitations to and literature about the Congress which was furnished to them by the Secretariat. In attempting to maintain the non-political nature of the Congress, many serious difficulties had to be overcome. In the solution of these problems, officers of the Congress found the various officials of the Department of State most sympathetic and helpful. As a part of the effort to keep the Congress apolitical, they tried to secure a visa for every mathematician who notified them about any visa difficulties before cancelling his passage. As far as they know only one mathematician from any independent nation was prevented from attending the Congress because he failed to pass a political test and this man did not notify the officers of the Congress about his difficulties. Only two mathematicians from occupied countries failed to secure visas. Mathematicians from behind the Iron Curtain were uniformly prevented from attending the Congress by their own governments who generally refused to issue passports to them for the trip to the Congress. Their non-attendance was not due to any action of the United States Government.

Just before the opening of the Congress there was received from the President of the Soviet Academy of Sciences the following cablegram:

"USSR Academy of Sciences appreciates receiving kind invitation for Soviet scientist take part in International Congress of Mathematicians to be held in Cambridge. Soviet Mathematicians being very much occupied with their regular work

${ }^{1}$ R. G. D. Richardson and J. L. Synge were also originally members of this Committee. Dean Richardson died July 17, 1949, while Professor Synge resigned from the Committee when he left the United States to assume his position at the Institute for Advanced Study in Dublin in August 1948. 
unable attend congress. Hope that impending congress will be significant event in mathematical science. Wish success in congress activities.

S. Vavilov, President, USSR Academy of Sciences."

This cablegram was read at the opening plenary session of the Congress which was held on Wednesday afternoon in the Sanders Theatre of Harvard University. This session was opened by Professor Garrett Birkhoff as Chairman of the Organizing Committee of the Congress. After the short address of welcome by Professor Birkhoff, Professor T. A. Skolem of the University of Oslo presented the name of Professor Oswald Veblen for the Presidency of the Congress. Professor Veblen was unanimously elected and then delivered his presidential address. This address will appear in full in the Proceedings of the Congress; these the Editorial Committee hopes will be published within a year. Immediately after this address, Professor Harald Bohr of the University of Copenhagen spoke on behalf of the Committee to award the Field's Medals. ${ }^{2}$ The medals were awarded to Professors Laurent Schwartz of the University of Nancy and to Atle Selberg of the Institute for Advanced Study. Professor Bohr gave an excellent résumé of the work of Schwartz on distributions and of the work of Selberg on the Riemann zeta function and his elementary proof of the celebrated prime number theorem. Professor Bohr's paper will appear in full in the Proceedings of the Congress.

There were in attendance at the Congress 2302 persons. These were distributed as follows:

American and Canadian members attending.......... 1429

Americans and Canadians attending as associate members. $\quad 539$

Members outside United States and Canada attending.... 271

Associate members outside the United States and Canada

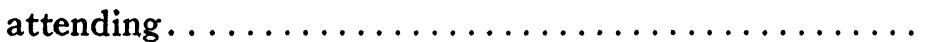

In addition there were a number of mathematicians who became members of the Congress but did not attend the gathering at Cambridge. Some of these joined fully expecting to be present but were prevented from attending either by illness or other unavoidable cir-

\footnotetext{
2 At the International Congress at Toronto in 1924 it was decided that at each international mathematical congress two gold medals should be awarded. Professor J. C. Fields, the Secretary of the 1924 Congress, presented a fund to subsidize these medals. They were first awarded in Oslo in 1936. The Committee to select the winners of the 1950 medals was: Professor Harald Bohr (Chairman), Professors L. V. Ahlfors, Karol Borsuk, Maurice Frechet, W. V. D. Hodge, A. N. Kolmogoroff, D. Kosambi, Marston Morse.
} 
cumstances while others assumed membership to support an enterprise which they considered most worthy. The statistics in this connection are as follows:

American and Canadian Congress members who did not at-

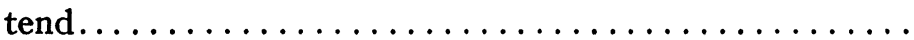

Associate American and Canadian Congress members who

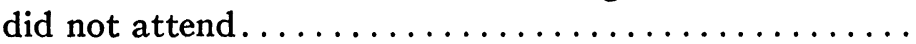

Congress members outside United States and Canada who

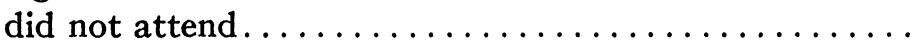

Associate members outside United States and Canada who did not attend.........................

Total Congress members who did not attend...... 248

Total Congress membership................ 2550

The following countries outside the United States and Canada were represented:

Argentina, Australia, Austria, Belgium, Brazil, Burma, Chile, China, Columbia, Cuba, Denmark, Egypt, Eire, England, Finland, France, Germany, Greece, India, Iran, Israel, Italy, Japan, Mexico, Netherlands, Nigeria, Norway, Panama, Peru, Philippines, Scotland, South Africa, Spain, Sweden, Switzerland, Turkey, Uruguay, Venezuela, Yugoslavia.

Every state in the Union was represented except South Dakota.

\section{The Scientific Program}

In addition to the contributed ten-minute papers and the stated addresses, which were delivered on invitation of the Organizing Committee, the scientific program of the Congress included four conferences on the following topics: Algebra, Analysis, Applied Mathematics, and Topology. The chairman of each section for contributed papers was given the privilege of inviting not more than three persons to deliver thirty minute addresses in his section.

\section{Stated AdDREsses}

The following stated addresses were delivered by invitation of the Organizing Committee:

A. A. Albert: Power-associative algebras.

Arne Beurling: On null-sets in harmonic analysis and function theory.

S. Bochner: Laplace operator on manifolds. 
H. Cartan: Sur les fonctions analytiques de variables complexes.

S. S. Chern: Differentiable geometry of fiber bundles.

H. Davenport: Recent work in the geometry of numbers.

Kurt Gödel: Rotating universes in general relativity theory.

W. V. D. Hodge: Topological invariants of algebraic varieties.

Heinz Hopf: Die n-dimensionalen Sphären und projektiven Räume in der Topologie.

Witold Hurewicz: Homology and homotopy theory.

S. Kakutani: Ergodic theory.

M. Morse: Recent advances in variational theory in the large.

J. von Neumann: Shock interaction and its mathematical aspects.

J. F. Ritt: Differential groups.

A. Rome: The calculation of an eclipse of the sun according to Theon of Alexandria.

L. Schwartz: Distributions and principal applications.

A. Wald: Basic ideas of a general theory of statistical decision rules.

A. Weil: Number-theory and algebraic geometry.

H. Whitney: $r$-dimensional integration in $n$-space.

N. Wiener: Comprehensive view of prediction theory.

R. L. Wilder: The cultural basis of mathematics.

O. Zariski: The fundamental ideas of abstract algebraic geometry.

\section{CONFERENCES}

In recent years mathematicians have been much impressed by the success of the conference method of presenting research in various fields in which vigorous advances have been made or are in progress. In such conferences there is a well-coordinated program of formal lectures and open informal discussion. At the International Congress the Organizing Committee decided to hold four conferences in the following fields: Algebra, Analysis, Applied Mathematics, and Topology. A number of the Stated Addresses listed above were integrated into the work of the Conferences.

A. Algebra Conference. The Algebra Conference was under the Chairmanship of Professor A. A. Albert.

There were four sessions, devoted to:

1. Algebraic geometry. In this session Professors A. Weil and O. Zariski gave their Stated Addresses.

2. Groups and universal algebra. The speakers were G. Birkhoff, H. Zassenhaus, S. MacLane, R. Baer, and C. Chevalley.

3. Structure theory of rings and algebras. The Stated Address of A. A. Albert was part of this session. Other speakers in this conference were R. Brauer, N. Jacobson, J. Dieudonné, and T. Nakayama. 
4. Arithmetic algebra. Principal speakers in this session were E. Artin, W. Krull, M. Deuring, and M. Krasner.

B. Analysis Conference. This Conference was under the Chairmanship of M. Morse and there were four sessions devoted solely to analysis with an additional section in which the participants of the Topology Conference were joined. This was held on Friday evening, September 1. The sessions were devoted to:

1. Analysis in the large. The speakers were L. Bers, S. Bergman, L. Cesari and T. Radô, and C. B. Morrey.

2. Extremal methods and geometric theory of functions of a complex variable. The speakers were L. V. Ahlfors, A. C. Schaeffer and D. C. Spencer, M. M. Schiffer, H. Grunsky, R. Nevanlinna, and G. Szegö.

3. Algebraic tendencies in analysis. This subconference consisted of reports of various aspects of the main topic of algebraic tendencies in analysis. A panel of experts surveyed the field and then prepared a report. This report of the panel was presented to the Congress by the spokesman of the group. Two sessions, one on Monday afternoon and the other on Tuesday, were devoted to this subconference. The topics treated were:

a. Group representations. Spokesman, R. Godement.

b. Topologic Algebra. Spokesman, I. Kaplansky.

c. Measure Theory. Spokesman, P. R. Halmos.

d. Spectral Theory. Spokesman, N. Dunford.

e. Applied Functional Analysis. Spokesman, N. Aronszajn.

f. Ergodic Theory. Spokesman, S. Kakutani.

4. The Joint Session with the Topology Conference was devoted to analysis and geometry in the large. The speakers were J. Leray, G. de Rham, and A. Lichnerowicz.

C. Conference in Applied Mathematics. This conference was under the Chairmanship of J. von Neumann. There were three sessions devoted to:

1. Random processes in physics and communications. The speakers were C. E. Shannon and S. M. Ulam.

2. Partial differential equations. The speakers were J. von Neumann, R. Courant, S. Goldstein, W. Heisenberg, W. Prager, J. J. Stoker. Professor von Neumann's address was the one which he presented by invitation of the Organizing Committee.

3. Statistical Mechanics. In this session there was the Stated Address of $\mathrm{N}$. Wiener. In addition W. Feller gave a 45 minute address.

D. Topology Conference. This conference was under the chairmanship of Hassler Whitney and was divided into four sessions. 
1. Homology and homotopy theory. The speakers were W. Hurewicz, S. Eilenberg, J. H. C. Whitehead, and G. W. Whitehead. Professor Hurewicz's address was given by invitation of the Organizing Committee.

2. Fiber bundles and obstructions. The speakers were P. Olum, W. S. Massey, G. Hirsch, and E. Spanier.

3. Differentiable manifolds. The speakers were S. Chern, E. Ehresmann, B. Eckmann, and C. B. Allendoerfer. Professor Chern's address was the Stated Address which he was invited to give by the Organizing Committee.

4. Topological groups. The speakers were P. A. Smith, Deane Montgomery, K. Iwasawa, A. Gleason, and R. H. Fox.

\section{Contributed Papers}

There were the usual sessions for the presentation of contributed papers. Each member of the Congress was given the privilege of submitting one paper for presentation in person. Presentation by title was not permitted. The contributed papers were distributed among seven sections, listed below. In addition, the Chairman of each section was permitted to invite not more than three persons to deliver thirty minute addresses in his section. ${ }^{3}$ In all 372 contributed papers were presented at the Congress.

Section I, Algebra and theory of numbers. Professor H. A. Rademacher was the chairman of this Section in which 58 contributed papers were presented. The following thirty minute addresses were given on invitation of the Chairman:

K. Mahler: Farey sections in the fields of Gauss and Eisenstein.

H. Selberg: The general sieve method and its place in prime number theory.

H. D. Kloosterman: The characters of binary modulary congruence groups.

Section II, Analysis. Professor G. C. Evans was the chairman of this Section in which 126 contributed papers were presented. The following invited addresses were given by invitation of the Chairman:

H. A. Rademacher: Remarks on the theory of partitions.

$\mathrm{H}$. Bohr: $A$ survey of the different proofs of the main theorems in the field of almost periodic functions.

S. Mandelbrojt: Theorèmes d'unicité de la theorie des fonctions.

Section III, Geometry and topology. Professor S. Eilenberg was the chairman of this Section in which 56 contributed papers were pre-

${ }^{8}$ An exception was later permitted in the section on Logic and Philosophy, where four persons presented these longer papers. 
sented. The following invited addresses were given by invitation of the Chairman:

L. A. Santaló: Integral geometry in general spaces (read by C. B. Allendoerfer).

B. Segre: Arithmetical properties of algebraic varieties.

Section IV, Probability and Statistics, Actuarial Science, Economics. Professor J. L. Doob was the chairman of this Section in which 27 contributed papers were presented. The following invited addresses were given by invitation of the Section Chairman:

C. Bose: Mathematical theory of factorial designs.

P. Levy: Processus laplaciens et équations différentielles stochastiques.

S. N. Roy: On some aspects of statistical inference.

Section V, Mathematical physics and applied mathematics. Professor Richard Courant was the chairman of this Section in which 74 contributed papers were presented. The following invited addresses were given by invitation of the Chairman:

C. G. Darwin: The refractive index of an ionized gas.

F. Rellich: Störungstheorie der Spektralzerlegung.

H. Lewy: Developments at the confluence of analytic boundary conditions.

Section VI, Logic and philosophy. Professor Alfred Tarski was the chairman of this Section in which 16 contributed papers were presented. The following invited addresses were given by invitation of the Chairman:

T. Skolem: Remarks on the foundation of set theory.

A. Tarski: Some notions and methods on the borderline of algebra and metamathematics.

A. Robinson: Applied symbolic logic.

S. C. Kleene: Recursive functions and intuitionistic mathematics.

Section VII, History and education. Professor C. V. Newsom was the chairman of this Section in which 15 contributed papers were presented. The following invited address was given by invitation of the Chairman:

G. Pólya: On plausible reasoning.

\section{The Social Program}

The entertainment of the members of the Congress was in the hands of an Entertainment Committee, whose chairman was L. H. Loomis. The other members of the Committee were C. R. Adams, Mrs. L. V. Ahlfors, Mrs. G. D. Birkhoff, J. A. Clarkson, Mrs. W. C. Graustein, F. B. Hildebrand, Evelyn M. Hull, J. R. Kline, E. R. 
Lorch, Mrs. W. T. Martin, E. B. Mode, G. A. O'Donnell, Mrs. H. B. Phillips, Helen G. Russell, J. H. Van Vleck, Mrs. J. L. Walsh, Mrs. D. V. Widder, Mrs. Norbert Wiener.

The members and associate members of the Congress were housed in the dormitories of Harvard University. Excellent meals were served in the Harvard Union. The local members of the Entertainment Committee arranged a fine exhibition of mathematical models and a book exhibit at the Harvard Cooperative Society. In addition to tours of Harvard University and the Massachusetts Institute of Technology there were trips to historic and modern Boston as well as to Lexington and to Concord.

On the opening night there was a reception for all members of the Congress at the Fogg Art Museum of Harvard University. On the following evening the Busch String Quartet gave a concert in the Sanders Theatre. At the same time Professor Howard Aiken, the designer of the Harvard Computing Machine, gave an interesting lecture on computing machines.

On Friday afternoon the mathematicians and their friends were the guests of Wellesley College at a tea. At the same time a restricted number of members of the Congress were admitted to the Harvard Observatory at Oak Ridge. On Saturday evening, September 2, there was an informal dance in Lowell House, while other members of the Congress attended a Beer Party in Memorial Hall.

There were no sessions of the Congress on Sunday, September 3. In the afternoon, Boston University received the members of the Congress and an organ recital was provided in the Daniel L. Marsh Chapel of the University. In the evening Richard Dyer-Bennet gave a concert of ballads of various nations in Sanders Theatre.

On Monday evening, September 4, the committee arranged for a concert in Symphony Hall by Miss Helen Traubel. The concert was enthusiastically received by the audience and Miss Traubel received a tremendous ovation at the end of the performance.

The Congress banquet was held on Tuesday evening, September 5, in the Sever Quadrangle. Professor Marston Morse was the Toastmaster and Dr. Detlev Bronk, President of the National Academy of Sciences, gave the principal address. Other speakers were Edward Crane, the Mayor of Cambridge; Dr. James R. Killian, the President of Massachusetts Institute of Technology; Professor W. V. D. Hodge, of Cambridge University; and Professor Percy Bridgeman of Harvard University. Professor Hodge expressed the sincere appreciation of our foreign members of the Congress to their American hosts for their splendid hospitality. 
On Wednesday evening, September 6, the mathematicians were the guests of the Director and Board of Trustees of Gardner Museum at a farewell party.

On Wednesday morning, September 6, there was held a final plenary session of the Congress in Sanders Theatre. Professor M. H. Stone gave a report on the conference which had been held in New York City immediately preceding the International Congress for the purpose of considering the formation of an International Mathematical Union. He reported that Statutes and By-Laws had been adopted and that these would be submitted to the proper scientific groups in the various national or geographic areas in which there was significant mathematical activity. When a specified number of groups have signified their acceptance of these Statutes and ByLaws, the Union will be declared in existence and a meeting of the General Assembly arranged.

Professor van der Corput, on behalf of the delegation from Holland, presented a cordial invitation to the International Congress to hold its next meeting in that country in 1954. The Congress unanimously voted to accept the gracious invitation of our Dutch colleagues. After addresses there was an address of appreciation by President Harald Cramér of the University of Stockholm. After Professor A. A. Albert had presented a resolution of thanks to Harvard University and the various committees of the Congress which was adopted unanimously, the Congress adjourned.

The Congress was undoubtedly the largest gathering of persons ever assembled in the history of the world for the discussion of mathematical research. However, the real measure of its success lies not in the large number of persons present, but in the excellence of its scientific program and in the contributions which it made to the cause of closer cooperation among scientists and to the cause of international good will.

J. R. KLINE, Secretary, International Congress of Mathematicians 